I. О. Процько

Львівський державний університет безпеки життєдіяльності, кафедра управління інформаційною безпекою

\title{
ОГЛЯД АЛГОРИТМІВ ЕФЕКТИВНОГО ОБЧИСЛЕННЯ ДПФ НА ОСНОВІ ЦИКЛІЧНИХ ЗГОРТОК
}

() Проиько I. O., 2016

Розглянуто підходи ефективного обчислення дискретних перетворень класу Фур'є на основі циклічних згорток. Описано сутність переформулювання базисних матриць перетворення ДПФ на блочно-циклічні структури для кожного підходу. Аналізуються переваги і недоліки алгоритмів для кожного підходу.

Ключові слова: швидке перетворення класу Фур'є (ШПФ), циклічна згортка, твірний масив.

\section{REVIEW THE ALGORITHMS OF THE EFFICIENT COMPUTATION OF DFT BASED ON CYCLIC CONVOLUTIONS}

(C) Ihor Prots'ko, 2016

The enumeration approaches of efficient computation discrete transform of Fourier class using cyclic convolutions is considered. The formulation of the basis matrix of transforms into the block cyclic structures is described of each approach. The analysis of the advantages and imperfections of the algorithms are discussed.

Key words: fast discrete transform of Fourier class, cyclic convolution, hashing array.

\section{Вступ}

Значною подією, пов'язаною із ще одним напрямком розвитку ефективних алгоритмів, яку зазначають у багатьох виданнях 3 цифрової обробки інформації $[1,2]$, є можливість ефективного обчислення ДПФ на основі циклічних згорток. Цей підхід розглядають як парадокс. Адже саме для виконання теореми про згортку в лінійних системах з постійними параметрами був запит на ШПФ, а виявляється, що ефективне обчислення ДПФ може зводитись до виконання швидких згорток.

Аналіз останніх досліджень

Одним з підходів до ефективного виконання дискретних перетворень класу Фур'є довільного обсягу є застосування для їх обчислення швидких циклічних згорток [2]. Для цього дискретний базис перетворення на основі декомпозиції приводиться до циклічних підматриць [3, 4]. Ці підматриці визначають ефективне обчислення дискретних перетворень класу Фур'є через виконання швидких циклічних згорток [5]. Аналіз останніх досліджень показав, що одержано різноманітні форми узагальненого опису перетворень класу Фур' $\epsilon$, приведених до обчислень через циклічні згортки. Однак існуючі підходи мають як свої переваги, так і особливості, що полягають у специфічній складності визначення обчислювальних алгоритмів для певних значень обсягів. Це потребує єдиного підходу до обчислень дискретних перетворень класу Фур'є для різних обсягів перетворення. 


\section{1. Алгоритми швидкого перетворення Фур'є на основі згорток}

Піонерською вважається публікація Ч. Рейдера (1968) [3], де дискретне перетворення Фур'є зводилось до обчислення циклічної згортки для послідовності обсягом, що дорівнює простому числу N. В основу приведення дискретного перетворення Фур'є:

$$
X(n)=\sum_{k=0}^{N-1} x(k) W^{n k}
$$

де $n, k=0, \ldots, N-1$, до циклічної згортки покладено переіндексацію порядку вхідної послідовності $x(k)$. Для цього застосовано первісний корінь $g$ з відповідним показником цілого степеня, що зводить добуток індексів до додавання показників степеня числа $g$. Тобто обчислення набуває вигляду:

$$
X\left(g^{n}\right)=\sum_{k=1}^{N-1} x\left(g^{-k}\right) W^{g^{n-k}}+x(0)
$$

що відповідає циклічній згортці без включення $x(0)$ [3]. Числу $g$ відповідає первісний корінь, не обов' язково один, з властивостями $g^{(\mathrm{N}-1)}=g^{(0)}=1, \quad g^{\mathrm{k}} \neq 1$, для $0<k<N-1$. При цьому враховують, що

$$
W^{n k}=W^{(n k) \bmod N}=W^{g^{n} g^{k}}=W^{g(n+k)}, W^{N}=1 .
$$

Алгоритм Рейдера можна застосовувати для обчислення ДПФ над будь-яким полем, якщо тільки обсяг перетворення $\mathrm{N} є$ простим числом. Первісний корінь $g$ використовують у структурі цього поля для періндексації вхідної послідовності і переходу до циклічної згортки.

У цей самий період 3'явилась робота Г. Герцеля (1968) [6], присв'ячена знаходженню окремих значень ДПФ через використання операції згортки. Алгоритм Герцеля не належить до ШПФ, оскільки його складність пропорціональна $O\left(N^{2}\right)$. Оскільки алгоритмами ШПФ обчислюють всі компоненти перетворення, то алгоритм Герцеля можна використовувати, коли необхідно визначити число вихідних компонент не більше за $\log _{2} N$ з $N$ компонент.

Відповідно до алгоритму Г. Герцеля обчислення $X(k)$, для $k=0,1, \ldots, N-1$, при $N$-точковій послідовності $x(n)$ виконують так. При кожному значенні $k$ для визначення $X(k), N$-точкова послідовність $X(k)$ 3'являється на виході системи, для якої $x(n)$ вхідна послідовність, а $W_{N}^{-n k} \epsilon$ імпульсною характеристикою цієї системи, потім з прийняттям $n=N$

$$
X(k)=\left.y_{k}(n)\right|_{n=N}, \quad y_{k}(n)=\sum_{q=1}^{N-1} x(q) W_{N}^{-k(n-q)} .
$$

Отже, $y_{k}(n)$ визначається як згортка заданої послідовності $x(n)$ та $W_{N}^{-n k}$, а $X(k)$ просто отримується прийняттям в $y_{k}(n)$ значення $n$ дорівнює $N$ [5].

У роботі Л. Блюстейна (1970) [7] також показано, що обчислення ДПФ може зводитись до виконання згортки. Наведемо основні викладки роботи

$$
X\left(e^{j \varphi_{k}}\right)=\sum_{n=0}^{N-1} x(n) e^{-j \varphi_{k} n},
$$

де $\varphi_{k}=\varphi_{0}+k \Delta \varphi, \quad \Delta \varphi=2 \pi / N$.

Позначимо $e^{-j \Delta \varphi}=W$, тоді, розписавши $\varphi_{k}$, отримаємо

$$
X\left(e^{j \varphi_{k}}\right)=\sum_{n=0}^{N-1} x(n) e^{-j \varphi_{0} n} W^{n k} .
$$

Замість степеня $\mathrm{W}$ запишемо $n k=(1 / 2)\left[n^{2}-k^{2}-(k-n)^{2}\right]$

$$
X\left(e^{j \varphi_{k}}\right)=\sum_{n=0}^{N-1} x(n) e^{-j \varphi_{0} n} W^{n^{2} / 2} W^{k^{2} / 2} W^{-(n-k)^{2} / 2} .
$$

Позначимо $z(n)=e^{-j \varphi_{0} n} W^{n^{2} / 2}$, i тоді отримаємо

$$
X\left(e^{j \varphi_{k}}\right)=W^{k^{2} / 2}\left(\sum_{n=0}^{N-1} z(n) W^{-(n-k)^{2} / 2}\right) .
$$

Визначення виразу $\sum_{n=0}^{N-1} z(n) W^{-(n-k)^{2} / 2}$ відповідає обчисленню згортки. 
Цей чірп-алгоритм переводить ДПФ обсягом $N$ до $N$-точкової циклічної згортки та $2 N$ додаткових добутків. Алгоритм містить $N$ множень, циклічну згортку із подальшими $N$-точковими множеннями. 3 обчислювального погляду алгоритм Блюстейна не відзначається ефективністю, повне число операцій має $N^{2}$ добутків, однак для певних застосувань він має простішу апаратну реалізацію.

На подальший розвиток алгоритмів 3 можливістю обчислення ШПФ через циклічні згортки вплинули роботи Гуда-Томаса $[8,9]$. ШПФ-алгоритм, що сильно відрізняєтья від алгоритму КуліТюкі [10], розробили І. Гуд (1958) і Л. Томас (1963) для випадку розкладення обсягу перетворення $N=r_{1} \times r_{2} \mathrm{x} \ldots \mathrm{x} r_{p}$ на взаємно прості множники $r_{1}, r_{2}, \ldots, r_{p}$.

В алгоритмі Гуда-Томаса перехід до багатовимірного перетворення ДПФ відбувається за китайською теоремою про залишки для цілих чисел і при цьому не потрібно виконувати добутки на повертаючі множники [10].

$$
X\left(k_{1}, k_{2}, \ldots, k_{p}\right)=\sum_{n_{1}=0}^{\eta_{1}-1} \sum_{n_{2}=0}^{r_{2}-1} \ldots \sum_{n_{p}=0}^{r_{p}-1} x\left(n_{1}, n_{2}, \ldots n_{p}\right) W^{n_{1} k_{1}} W^{n_{2} k_{2}} \ldots W^{n_{p} k_{p}},
$$

де $\quad W^{n k}=\exp (-j 2 \pi k n / N T)$; обсяг послідовності $N=\prod_{i}^{p} r_{i}$ складеного числа вимагає попарної взаємної простоти множників $r_{i}$ розкладу обсягу $N$ послідовності перетворення. При цьому обчислення ДПФ може зводитись до виконання циклічних згорток над меншими обсягами послідовностей, що відповідають простим множникам $r_{i}$ розкладу обсягу $N$ перетворення ДПФ.

Розвиваючи наведені напрацювання в царині ефективних алгоритмів, Ш. Віноград (1976) [11] опублікував ефективніший, але й складніший алгоритм Вінограда для ДПФ (АВПФ), що зменшував кількість множень порівняно з базовим алгоритмом Кулі-Тюкі за основою два приблизно в п'ять разів [12].

У роботі Ш. Вінограда [13] розвинено підхід Рейдера приведення до циклічних згорток ДПФ послідовностей обсягом простого та степеня простого числа, а також в ній виведено формулу обчислювальної складності ДПФ для мінімальної мультиплікативної складової. В алгоритмах Вінограда для переіндексації порядку вхідних даних використовують конкретні обчислення, що грунтуються на китайській теоремі про залишки, властивості прямого добутку матриць та алгоритмі швидких циклічних згорток. Виведення АВПФ призначається для ефективного обчислення ДПФ невеликих (малих) обсягів, що зводиться до приведення обчислення через циклічні згортки 3 використанням модульної арифметики в кільці поліномів. У випадку рівності обсягу перетворення простому числу $N$ перший крок полягає у заміні ДПФ за алгоритмом Рейдера циклічною згорткою, що обчислюється за алгоритмом Вінограда для згорток малого обсягу. Структура алгоритму Вінограда для згорток спочатку виконує певну кількість додавань, потім множень, і потім знову відповідну кількість додавань. Тобто, одержані АВПФ можна подати в так званому гніздовому представленні, де всі множення багатовимірного обчислення зосередженно між вхідними i вихідними етапами об'єднання

$$
X=O D I x,
$$

де $x, X-$ відповідно, вхідний і вихідний стовпці даних; $I-$ одинична матриця $(\mu \times \mathrm{N})$, описує об'єднання вхідної послідовності; $D$ - діагональна матриця множників $(\mu \times \mu) ; O$ - одинична матриця $(\mathrm{N} \times \mu)$, описує вихідні об'єднання; в загальному випадку $\mu>\mathrm{N}$. "Гніздова" структура алгоритму Вінограда порівняно з поширеними потребує на $80 \%$ менше операцій множення за приблизно однакової кількості додавань [14].

У випадку рівності обсягу перетворення степені простого числа $N^{r}$ за алгоритмом Вінограда спочатку з множини $\left\{1,2,3,4, \ldots, N^{r}-1\right\}$ відділяють числа, кратні $N$. Цю підмножину приводять до циклічної згортки обсягом $\left(N^{r}-1\right)(N-1)$, що утворює основу алгоритму. Відділені $\left(N^{\mathrm{r}}-1\right)$ рядків та стовпців можна обчислити за алгоритмом Вінограда для згорток ще меншого обсягу.

Наприклад, $\mathrm{N}=3^{2}=9$ виділяємо, згрупувавши числа $0,3,6$, відповідно залишається основа 3 6-точкової згортки та чотирьох 2-точкових згорток. Отже, матриця розміру $N^{r}$ х $N^{r}$ розділяється на 
$\left(N^{r}-N^{r-1}\right)$-точкову циклічну згортку та $\left(N^{r-1}+1\right)$ циклічну згортку обсягом $(N-1)$ точок, які обчислюються алгоритмом Вінограда для згорток, що містить тільки уявні і дійсні множення [2].

У випадку рівності обсягу перетворення складеному числу $N=N_{1} \mathrm{x} N_{2} \mathrm{x} \ldots \mathrm{x} N_{\mathrm{k}}$, де взаємно-прості числа, алгоритм Вінограда грунтується на представленні матриці обсягом $N$ у вигляді прямого добутку матриць $N_{\mathrm{i}}$ точкових ДПФ

$$
W_{N}=>W_{\otimes}=W_{N 1} \otimes W_{N 2} \otimes \ldots \otimes W_{N k}
$$

та приведення обчислення $\mathrm{N}_{\mathrm{i}}$ точкових ДПФ до обчислення циклічних згорток із застосуванням модульної арифметики в кільці поліномів. Матриці $W_{N}$ i $W \otimes$ збігаються при перестановці (і не одній) їхніх рядків і стовпців. Правило переупорядкування інформаційних даних грунтується на китайській теоремі про залишки. На практиці зручніше переставляти компоненти вхідних і вихідних даних.

Проте ці алгоритми мають свої специфічні особливості для кожного розміру N, пов' язаного 3 переіндексацією вхідної послідовності і, отже, отримали нерегулярні структури. Тобто, алгоритми Вінограда досліджують і вдосконалюють автори $[12,14,15]$.

Існують інші роботи з теоретичного обгрунтування можливості обчислення ДПФ через обчислення згортки [16].

\section{2. Подальший розвиток обчислення дискретних перетворень класу Фур'є з використанням циклічних згорток}

Поряд 3 проведенням досліджень ефективного виконання дискретних перетворень Фур'є в комплексній області розвивались і взаємодоповнювались підходи ефективного обчислення перетворень в дійсній області. Обширні теоретичні дослідження ортогональних гармонічних базисних систем привели до створення в кінці 70-х років теорії узагальненого спектрального аналізу, яка дала змогу створити методи й критерії синтезу дійсних базисних систем. Це дискретне косинусне перетворення (ДКП), дискретне синусне (ДСП) та перетворення Хартлі (ДПХ) та їхні види, що задаються за відповідних значень коефіцієнтів зміщення. Ці перетворення називатимемо дійсними дискретними гармонічними перетвореннями (ДГП) або дискретними перетвореннями класу Фур'є.

Швидкі циклічні згортки призводять до ефективних обчислень ДГП, в основу яких покладено перебудову ядра базисної матриці перетворення в набір циклічних структур. Для багатьох відомих швидких алгоритмів застосовують суто алгебраїчні методи. У роботі [17] показано, що у випадку, коли обсяг $p$ - просте число і таке, що ( $p-1) / 2$ непарне, то ДКП можна обчислити через виконання двох циклічних згорток з розмірностями кожної $(p-1) / 2$. У роботі [18] пропонується розкласти обчислення $N$ - точкового ДКП на добуток двох матриць, де кожна матриця має обсяг $(M-1) \times(M-1)$ i $M=N / 2$. Кожна 3 розкладених матриць добутку перетворюється на пару [(M-1)/2]-точкових циклічних згорток.

Подальший розвиток обчислення дискретних перетворень Фур'є класу на основі циклічних згорток використовує узагальнені схеми ефективних алгоритмів, що теоретично обгрунтовують можливості переформулювання до блочно-циклічних структур базису ДГП.

Стратегію ідентифікації циклічних або асиметрично циклічних структур всередині базисної матриці ДГП досліджено в багатьох роботах. Загальне рішення пропонується реалізувати для ДКП довільного обсягу за допомогою циклічних згорток в алгоритмі Чана-Ciy (Chan-Ciy) [19]. Прямий та інверсний алгоритм дискретного косинусного перетворення довільного обсягу $N$ формулюють за допомогою двох лінійних згорток довжини $N$ або через утворення двох циклічних згорток. Отже, обчислення можна легко реалізувати за допомогою технологій, які добре підходять для виконання згорток. У цьому алгоритмі зроблено такі зміни, що ми можемо використовувати циклічні згортки

$$
\begin{aligned}
& \mathrm{Y}(\mathrm{k})=\{2 \mathrm{~T}(\mathrm{k})+\mathrm{x}(0)\} \cos (\mathrm{k} \pi / 2 \mathrm{~N}), \quad \mathrm{k}=0,1, \ldots, \mathrm{N}-1 ; \\
& \mathrm{T}(\mathrm{k})=1 / 2[\mathrm{H}(\mathrm{k})+\mathrm{H}(2 \mathrm{~N}-\mathrm{k})+\mathrm{G}(\mathrm{k})+\mathrm{G}(2 \mathrm{~N}-\mathrm{k})] \sec \left[\mathrm{k}^{2} \pi / 2 \mathrm{~N}\right] .
\end{aligned}
$$


Для елементів послідовності $\{\mathrm{T}(\mathrm{K})\}$ спочатку обчислюють дві послідовності $\{\mathrm{H}(\mathrm{K})+\mathrm{H}(2 \mathrm{~N}-\kappa)\}$ i $\{\mathrm{G}(\mathrm{K})+\mathrm{G}(2 \mathrm{~N}-\kappa)\}$, які обидві задані в формі циклічної згортки. Це ефективний і дієвий підхід, оскільки за його допомогою уникають складної маршрутизації даних та управління даними. Цей алгоритм не $є$ оптимальним 3 погляду обчислювальної складності, але містить деякі регулярні форми, які є найпридатніші для реалізації з використанням технологій і конструкцій, які добре підходять для виконання згорток. 3 іншого боку, цей алгоритм $є$ гнучкішим, оскільки його можна застосувати для реалізації прямого та зворотного ДКП довільного обсягу.

У роботі [20] розглянуто узагальнений алгоритм Вага (M. Wagh), який складається з розбиття ядра ДКП на підматриці, які через переставлення відповідних рядків і стовпців і заперечень відповідають еквівалентним груповим таблицям (або їх частинам) для відповідних абелевих груп. В роботі визначено узагальнену згортку, що сформульована від абелевої групи $G$. Індексація послідовностей $u$ і $v$ визначається через елементи групи $G$. Тоді їх згортка для послідовності $w$ задається як

$$
w(h)=\sum_{g} u(g) v(n \circ g)
$$

$\mathrm{Te}$, що цю згортку відносно до $G \cong C_{\mathrm{nl}} \mathrm{x} C_{\mathrm{n} 2} \mathrm{x} \ldots$ х $C_{\mathrm{nr}}$ можна обчислити через $W=U * V$, де $U$, $V$, і $W \in r$-мірні масиви і * означає $r$-вимірну циклічну згортку. Обчислення, що належить до сформованих підматриць, можна здійснити з використанням багатовимірних циклічних згорток. Інакше кажучи, робота алгоритму основана на абелевій групі додатніх цілих чисел, взаємно простих з $N$ або менше $N$ з множенням за модулем $N$. Групу і групову операцію визначають як $A$ $\langle N$, *>. В статті доведено теорему 1 , що відповідає загальному обчислення ДКП через циклічні згортки послідовностей, сформованих за правилом відповідності. Проте визначення циклічних підматриць в структурі базисного ядра перетворення ускладнюється через визначення значного числа елементів для переіндексації і, відповідно підвищують складність синтезу обчислювального алгоритму.

У роботах $[21,22]$ розглянуто узагальнену методику для ефективного обчислення типів ДГП для послідовностей довільного числа точок з використанням циклічних згорток. Сформовані твірні масиви в алгоритмі визначають розбиття гармонічного ядра перетворення на підматриці, які можна отримати за допомогою перестановки з рядків і стовпців базису. Використовувані в алгоритмах синтезу твірні масиви універсальніші і переважно кращі 3 погляду відображення індексації порівняно з існуючими алгоритмами.

Алгебраїчна система $\langle N-1, *\rangle$ з операцією на множині $(1,2, \ldots, N-1)$ еквівалентна базисній матриці ДГП. У разі, якщо обсяг перетворення $N$ просте, алгебраїчна система $\langle N-1$, * $\rangle$ представляє циклічну абелеву группу. Таблиця операцій цієї алгебраїчної системи $є$ ганкелева кругова матриця. Елементи циклічної групи дорівнюють натуральному степеню генеруючого елемента $\alpha \in \mathrm{G}$. Генеруючий елемент $a$ циклічної групи $\epsilon$ примітивним коренем, і $\alpha$ не $\epsilon$ єдиним. Примітивним елементом буде $\alpha^{N-1}$ також. Отже, всі елементи циклічної групи можна визначити степенями примітивного елемента. Непримітивні елементи циклічної групи генерують частину набору 3 множини, а інша частина набору формується шляхом множення двох елементів за модулем $\mathrm{N}$. Проаналізуємо ганкелеву матрицю аргументів розмірності $(N \mathrm{x} N)$ як підстановку $\pi_{\mathrm{i}}$ для кожного рядка/стовпця $a_{\mathrm{i}}, \mathrm{i} \in\{1,2, \ldots, x\}$ до першого рядка/стовпця матриці, коли $N \in$ простим числом.

Набір підстановок $\Psi=\left\{\psi_{1}, \psi_{2}, \psi_{3}, \psi_{4}, \psi_{5}, \ldots, \psi_{x}\right\} 3 \circ-$ операцією над підстановками формує циклічну групу. Кількість генеруючих і непримітивних елементів однакова для алгебри < $\Psi$, о> $\mathrm{i}$ алгебри $\langle N-1, *\rangle$ з операцією множення аргументів $(*=(n \times k)$ за модулем $N)$. Ппідставляючи рядки/стовпці з даних базисної матриці, сформуємо $P(n)$ твірний масив, що відповідає циклічному розкладу підстановки

$$
\begin{aligned}
P(n)=P\left(n_{1}\right) P\left(n_{2}\right) \ldots P\left(n_{k}\right)= & \left(n_{11,} n_{12}, n_{13, \ldots,}, n_{1 L 1}\right)\left(n_{21}, n_{22,}, n_{23, \ldots,} n_{2 L 2}\right)\left(n_{k 1}, n_{k 2}, \ldots, n_{k L k}\right), \\
n & =\left(L_{1}+L_{2}+\ldots+L_{k}\right) .
\end{aligned}
$$

Цей $P(n)$ твірний масив відповідає спрощеному $P^{\prime}(n)$ твірному масиву з доповненим масивом знаків $S(n)$, які дають змогу надалі скоротити процес обчислення. Сформований твірний масив стисло описує блочно-циклічні структури базису матриці ДГП. Аналіз структури базисної матриці 
визначає специфіку обчислювального алгоритму для різних типів ДГП. Паралелізм і низька складність цих алгоритмів добре підходять для реалізації у вигляді програмного забезпечення [23] та економно реалізуються у вигляді інтегральних схем.

\section{Висновки}

Розвиток ефективних обчислень дискретних гармонічних перетворень 3 використанням циклічних згорток пройшов шлях від визначення окремих дискретних компонентів, від обсягів, що дорівнюють простому числу, від довжини перетворень, що дорівнюють добутку простих множників, не взаємно простих множників обсягів до алгоритмів для довільного обсягу послідовності перетворення. Запропоновані методи індексації можуть переформувати обсяг перетворення до іншого набору менших обсягів циклічних структур. Деякі 3 алгоритмів не є оптимальними 3 погляду мінімізації обчислювальної складності. Однак, ефективні алгоритмічні схеми дискретного перетворення Фур'є класу з використанням циклічних згорток користуються підвищеною увагою виробників інтегральних схем. Адже цей підхід забезпечує значну ефективність в апаратній реалізації із застосуванням технологій НВIC. Реалізація циклічних згорток або структур кругової кореляції забезпечуе високу швидкість виконання, низьку складність обчислення, малу кількість вхідних/вихідних контактів.

1. R. E. Blahut, Fast Algorithms for Signal Processing, Cambridge University Press, 2010. 2. Гольденберг Л. М., Матюшкин Б. Д., Поляк М. Н., Цифровая обработка сигналов: Справочник. M.: Радио и связь, 1985. - 312 с. 3. Rader C. M., Discrete Fourier transform when the number of data samples is prime. Proc.IEEE 56, 1968, p. 1107-1108. 4. R. Tolimiery, M. An, C. Lu, Algorithms for Discrete Fourier Transform and Convolution, New York, Springer-Verlag, 1997 (s.ed.). 5. McClellan J. H., Rader C. M., Number Theory in Digital Signal Processing, Prentice Hall, Englewood Cliffs, NJ, 1979. 6. Goertzel G. An algorithm for the evaluation of finite trigonometric series. - Amer. Math. Mon., 1968, v.65, p. 34-35. 7. Bluestein L. I. Linear filtering approach to the computation of discrete Fourier transforms. -IEEE Trans. Audio Electroacoust., 1970, v.AU-18, p. 451-455. 8. Good I. J., "The interaction algorithm and practical Fourier analysis", J. Roy. Stat. Soc. B-20, pp. 361-372, 1958; vol. 22, pp. 372-375, 1960. 9. Thomas L. H., "Using of computer to solve problems in physics". -In Applications of digital computers, Boston: Ginn and Со., 1963. 10. Рабинер Л., Гоулд Б. Теория и применение иифровой обработки сигналов. - М.: Мир, 1978. - 848 c. 11. Winograd S., "On computing the discrete Fourier transforms", Proc. Nat. Acad. Sci. USA, vol. 73, pp. 1005-1006, 1976. 12. Zohar S., "Faster Fourier Transformation: The Algorithm of S. Winograd”, Jet Propulsion Laboratory JPL Publication 78-104, under NASA Contract No. NAS7-100, pp. 1-93, February 15, 1979. 13. Winograd S., "On computing the discrete Fourier transforms", Mathematics of Computation, vol. 32, рр. 175-199, 1978. 14. Нуссбаумер Г. Дж. Быстрое преобразование Фурье и алгоритмы вычисления сверток. -М.: Радио и связь, 1985. - 248 c. 15. Kolba D. P., Parks T. W., “A Prime Factor FFT Algorithm Using High Speed Convolution”, IEEE Trans, on Acoustics, Speech, and Signal Processing ASSP-25, pp. 281-294, 1977. 16. Гагарин Ю. И., Рекурсивное преобразование Фурье через свертки. Проблемы передачи информации. - 1989. - T. ХХV, Bыл. 4, С. 93-95. 17. Muddhasani D. P. V., Wagh M. D., "Bilinear algorithms for discrete cosine transforms of prime lengths", Signal Processing, vol. 86, no. 9, pp. 2393-2406, 2006. 18. Meher P. K., "Systolic designs for DCT using a low complexity concurrent convolutional formulation", IEEE Trans. Circuits \& Systems for Video Technology, vol. 16, no. 10, pp.1041-1050, 2006.19. Chan Y. H., Siu W. C., "Generalized approach for the realization of discrete cosine transform using cyclic convolutions", in: Intl. Conf. on Acoustics, Speech and Signal Processing ICASSP'93, vol. 3, pp. 277-280, 1993. 20. Wagh M. D., Ganesh H., "A new algorithm for the discrete cosine transform of arbitrary number of points", IEEE Trans. on Computers, C-29 (4), pp. 269-277, 1980. 21. I. Prots'ko, "Algorithm of Efficient Computation of DCT I-IV Using Cyclic Convolutions", International Journal of Circuits, Systems and Signal Processing, vol. 7, is. 1, pp. 1-9, 2013. 22. I. Prots'ko, "Algorithm of efficient computation of generalized discrete Hartley transform based on cyclic convolutions", IET Signal Processing, vol.4, is. 4, pp. 301-308, 2014. 23. I. Prots'ko, R. Rikmas, V. Teslyuk, The program implementation of the synthesis the efficient algorithms for computation of DCT-II via cyclic convolutions. Proceeding of the IX $X^{\text {th }}$ International Scientific and Technical Conference (CSIT'2014), Lviv, 18-22 November 2014. - P. 116-118. 